\title{
Poly(CL/DLLA-b-CL) multiblock copolymers as biodegradable thermoplastic elastomers
}

\author{
T. Ryynänen ${ }^{1}$, A. Nykänen ${ }^{2}$, J. V. Seppälä ${ }^{*}$ \\ ${ }^{1}$ Helsinki University of Technology, Department of Chemical Technology, Laboratory of Polymer Technology, \\ P.O. Box 6100, FI-02015 TKK, Finland \\ ${ }^{2}$ Helsinki University of Technology, Department of Engineering Physics and Mathematics, Laboratory of Optics and \\ Molecular Materials, P. O. Box 2200, FI-02015 TKK, Finland
}

Received 23 October 2007; accepted in revised form 19 January 2008

\begin{abstract}
Lactic acid and $\varepsilon$-caprolactone based polymers and their derivates are widely used in biomedical applications. Different properties are introduced by modifying the composition. In this study, poly( $\varepsilon$-caprolactone/D,L-lactide)-b-poly( $\varepsilon$ caprolactone) multiblock copolymers were synthesized as poly(ester-urethane)s (PEUs) by polymerizing in two steps involving ring-opening polymerization of precursors and by diisocyanate linking of precursors to produce thermoplastic elastomers (TPEs). The precursors and products were characterized by SEC, ${ }^{1} \mathrm{H}-\mathrm{NMR}$ and DSC, and dynamic mechanical study (by dynamic mechanical analysis, DMA) as well as morphological characterization (by transmission electron microscopy, TEM) of the product TPEs was carried out. Tensile and creep recovery properties of them were also studied. According to the characterizations, all the polymerizations were successful, and the prepared TPEs showed clear elastic behavior. In the DMA scans, rubbery plateau in the storage modulus curves between $T_{g}$ and terminal flow region was clearly detectable indicating elasticity. The TEM images demonstrated phase separation of amorphous and crystalline blocks when the degree of crystallinity of the hard blocks was high enough. The elongations of TPEs varied between 800-1800\%, while the modulus was 7-66 MPa. Two different types of recovery tests indicated the creep properties of TPEs to be highly dependent on the degree of crystallinity.
\end{abstract}

Keywords: biodegradable polymers, lactide, E-caprolactone, poly(ester-urethane)s (PEUs), thermoplastic elastomers (TPEs)

\section{Introduction}

Widening the range of mechanical properties of biodegradable polymers has been increasingly studied for last decades. Ever-growing applications scope of biomaterials runs efforts to design polymers with new more sophisticated characteristics. One of often favorable characteristic for biomedical materials is elasticity. Elasticity is traditionally achieved by cross-linking techniques and the rubbery properties are resulting from the chemical network structure of thermosets [1]. However, in many biomedical applications, thermoplasticity of an elastomer is a highly favourable property enabling processing, remoulding and even injection of the elastomer in situ. This kind of thermoplastic elastomers (TPEs) can be prepared by introducing phase-separating blocks in the polymer chain so building up physically cross-linked reversible network [2].

TPEs typically are block copolymers consisting of amorphous soft segments and crystalline hard segments. There are only a few different polymerization methods that have been used to prepare biodegradable block copolymer structured elas-

*Corresponding author, e-mail: jukka.seppala@tkk.fi

(C) BME-PT and GTE 
tomers. One of those methods is chain extension where different types of precursors are linked to produce high molecular weight block copolymers with linking agents. Chain extension method in block copolymerization has formerly been utilized in the biopolymer group of our laboratory [3-8], and in some other groups [9-11]. The most widely used linking agents have been diisocyanates which combine hydroxyl terminated precursors to poly(ester-urethane)s. In addition to that, several research groups have prepared block copolymer structures by living ring-opening polymerization, or by something close to that, using pre-prepared macroinitiators (segment $A$ ) to initiate the ringopening polymerization of segment B [12-16]. Newer polymerization techniques, such as atom transfer radical polymerization (ATRP), have been utilized to make the control of the resulting block copolymer architecture more precise [17].

Along with development of different polymerization methods, the variety of monomers and different compositions of block copolymers have been key factors in the design of TPEs. The use of conventional biopolymer monomers such as different lactones has been widely reported in literature [9-17]. Typically semi-crystalline poly(L-lactide) and poly(D-lactide) have been used as the hard blocks [9-18] while amorphous poly( $\varepsilon$-caprolactone) $[10-12,18]$, poly (1,3-trimethylene carbonate) [13-15] and poly(ethylene oxide) [19] have been often used as soft components in block structured biodegradable TPEs.

This study is natural continuum of the earlier work in the field of poly(ester-urethane)s carried by our biopolymer group in Helsinki University of Technology [1, 3-7]. In this study, poly( $\varepsilon$-caprolactone/ D,L-lactide)-b-poly( $\varepsilon$-caprolactone) multiblock copolymers were synthesized to produce biodegradable thermoplastic elastomers. The objective was to enhance the recovery and creep properties of amorphous poly( $\varepsilon$-caprolactone/D,L-lactide) copolymers by linking semicrystalline poly( $\varepsilon$-caprolactone) blocks between linear polymer chains. In other words, the purpose was to achieve physical cross-linking by secondary hydrogen bonds between polymer chains by adding crystalline segments to an amorphous copolymer. Poly( $\varepsilon$-caprolactone) was chosen to act as hard block as it is known capable to crystallize
$[7,20]$. The CL/DLLA semi-random copolymers in molar compositions of 30/70, 50/50 and 70/30 were chosen to act as soft blocks because they were known to be fully amorphous by the study of Hiljanen-Vainio et al. [20]. The aim was to evaluate the effect of different quantities of crystalline phase to the recovery properties of the TPEs. Thus mechanical and recovery properties of these TPEs were rather extensively studied in addition to thermal and dynamic mechanical tests.

\section{Experimental}

\subsection{Materials}

The poly( $\varepsilon$-caprolactone/D,L-lactide) and poly( $\varepsilon$ caprolactone) precursors were polymerised from D,L-lactide (DLLA; Purac) and $\varepsilon$-caprolactone (CL; Solvay). DLLA was recrystallized from toluene and CL was dried over molecular sieves. Stannous octoate ( SnOct $_{2}$; Sigma) and 1,4-butanediol (BD; Fluka Chemica) were used as received in the ringopening polymerization of precursors. In the linking reaction, 1,6-hexamethylenediisocyanate (HMDI) was used, without further treatment, as chain extender.

\subsection{Preparation of poly( $\varepsilon$-caprolactone/ D,L-lactide) and poly( $\varepsilon$-caprolactone) precursors}

The poly( $\varepsilon$-caprolactone/D,L-lactide) and poly( $\varepsilon$ caprolactone) precursors, respectively amorphous and semicrystalline segments of the elastic poly(ester-urethane) multiblock copolymers, are denoted by $\mathrm{P}(\mathrm{CL} / \mathrm{DLLA}-\mathrm{BD})$ and $\mathrm{P}(\mathrm{CL}-\mathrm{BD})$, and e.g., by $\mathrm{P}(30 / 70-1)$ and $\mathrm{P}(100-1)$. The precursors were polymerized in melt from CL and DLLA at $160^{\circ} \mathrm{C}$ under nitrogen atmosphere for six hours in a batch reactor designed for agitation of viscous materials. The monomers were fed to the reactor with an appropriate amount of 1,4-butanediol as coinitiator $(0,5,1,0$ or 5,0 per 100 monomer units) for hydroxyl termination and control of molecular weight of the precursor. Stannous octoate was used as initiator with amount of $0,02 \mathrm{~mol} \%$. The reaction procedure is thoroughly discussed in the previous publication of our group by Helminen et al. [1]. 


\subsection{Chain extension of precursors into elastic poly(ester-urethanes)}

PEUs were polymerized in a $200 \mathrm{ml}$ round-bottomed flask reactor equipped with one-armed stirrer. Precursors were first added to the reactor in the molar ratio of $1: 1$ and melted at $160^{\circ} \mathrm{C}$ in argon atmosphere before $30 \mathrm{~mol} \%$ excess of 1,6-hexamethylene diisocyanate as chain extender was fed to the reactor. In earlier work by our group [3] on the chain extending reactions of isocyanates with hydroxyl groups, the high temperature was introduced as a means to avoid the use of solvents and catalysts typically used in the functionalization of hydroxyl groups with isocyanates. If high temperatures are allowed a more straightforward route to the desired products is achieved without the use of these additional components. The amount of HMDI was calculated from the theoretical molecular weight of the synthesized precursors, and the $30 \mathrm{~mol} \%$ excess used in linking reactions results from earlier experience in diisocyanate chemistry in our group [3,4]. The reaction time was 712 minutes determined of the growth rate of the viscosity of the reaction mixture.

\subsection{Characterisations}

Molecular weights $\left(M_{n}\right.$ and $\left.M_{w}\right)$ and molecular weight distributions (MWD) were determined relative to polystyrene standards by size exclusion chromatography (SEC). The Waters Associates system was equipped with a Waters 717 plus autosampler injector, a Waters 510 HPLC solvent pump, four linear PL gel columns $\left(10^{4}, 10^{5}, 10^{3}\right.$, and $100 \AA$ ) connected in series, and a Waters 2414 refractive index detector. All samples were analyzed at room temperature. Chloroform (Riedel-de Haën; stabilized with $1 \%$ ethanol) was used as eluent, and was delivered at a flow rate of $1,0 \mathrm{ml} / \mathrm{min}$. The samples were dissolved in chloroform at a concentration of $1,0 \%(\mathrm{w} / \mathrm{v})$. The injection volume was $200 \mu \mathrm{l}$.

For ${ }^{1} \mathrm{H}-\mathrm{NMR}$ measurements, the samples were dissolved in chloroform- $d_{1}$ (Aldrich; deuteration degree not less than 99,8\%) in $5 \mathrm{~mm}$ NMR tubes at room temperature. The sample concentration was about $1,0 \%$ by weight. NMR spectra were recorded on a Varian Gemini $2000300 \mathrm{MHz}$ NMR spectrometer working at $300032 \mathrm{MHz}$ for proton.
Differential scanning calorimetric (DSC) measurements were carried out on a Mettler Toledo Star ${ }^{\mathrm{e}}$ DSC $821^{\mathrm{e}}$. The measurements were run from -100 to $180^{\circ} \mathrm{C}$ at heating and cooling rates of $10^{\circ} \mathrm{C} \cdot \mathrm{min}^{-1}$. The glass transition temperatures $\left(T_{g}\right)$, melting temperatures $\left(T_{m}\right)$, and melting endotherms $(\Delta H)$ of the precursors and linked elastomers were measured during the second heating period.

Dynamic mechanical analysis (DMA) was performed on a Perkin-Elmer 7 Series instrument. The specimens were die-cut from 2,0 $\mathrm{mm}$ thick hotpressed polymer plate. The measurements were carried out using the three-point bending geometry (sample size $2,0 \times 5,0 \times 18,0 \mathrm{~mm}$ ) over a temperature range of -70 to $60^{\circ} \mathrm{C}$ at a rate of $4^{\circ} \mathrm{C} \cdot \mathrm{min}^{-1}$. All measurements were carried out at $1 \mathrm{~Hz}$.

Transmission electron microscopy (TEM) was used in morphological studies of the TPEs. Contrast for the morphological characterization was achieved by a sample preparation technique that relies on different rates of diffusion of a $\mathrm{RuO}_{4}$ stain into the amorphous and semi-crystalline regions [21]. First, the sample surface was cut at temperature of $-100^{\circ} \mathrm{C}$ to make a smooth surface for the stain to penetrate into the sample. The samples were then stained in vapor of $0,5 \% \mathrm{RuO}_{4}$ stabilized aqueous solution (Electron Microscopy Science) for a period of three days. The stained sample was microtomed using a Leica Ultracut UCT ultra-microtome with a diamond knife at temperature of $-100^{\circ} \mathrm{C}$, and $70 \mathrm{~nm}$ thick sections were collected on 300 mesh sized lacey carbon coated copper grids. Bright field TEM was performed with Tecnai 12 transmission electron microscope using $120 \mathrm{kV}$ accelerating voltage.

Tensile properties of the samples were measured with an Instron 4204 tensile testing machine applying the standard ISO 6239-1986 for small test specimens. The specimens were die-cut with a bone shaped die-cut head from the same $2,0 \mathrm{~mm}$ thick polymer plate as the specimens for DMA tests. To find out the difference on tensile properties occurred by different preparing methods of the samples, some parallel tests were also run with injection moulded specimens. The moulding temperatures were between 70 to $150^{\circ} \mathrm{C}$ and the injection moulding pressure was 6 bar. The tensile tester was equipped with $1 \mathrm{kN}$ load cell and was operated at crosshead speed of $20 \mathrm{~mm} \cdot \mathrm{min}^{-1}$. The tensile strength, strain and modulus of the polymers were 
measured for three to five parallel specimens that had been air-conditioned for $72 \mathrm{~h}$ at $23^{\circ} \mathrm{C}$ and $50 \%$ relative humidity.

The first series of recovery tests were run on an Instron 4204 tensile testing machine using the same type of small die-cut bone shaped test specimens as on tensile testing. The crosshead speed was $20 \mathrm{~mm} \cdot \mathrm{min}^{-1}$ and the samples were strained to $100 \%$ elongations. After 10 minutes recovery time the permanent deformations were measured. Tests were carried out in duplicate for air-conditioned specimens. The second series of recovery tests were run by Perkin-Elmer 7 Series DMA instrument for film samples. The dimensions of the film shaped samples were $5 \times 17 \mathrm{~mm}$, and they were cut out from $0,1 \mathrm{~mm}$ thick hot-pressed polymer film. The samples were tested in tensile mode. Constant stress of $2 \mathrm{MPa}$ (1 MPa for TPE(70/30-1)-b-(1005)) was applied for 10 minutes and the $\%$-strain was observed as function of time. After 10 minutes, the stress was dramatically dropped to $9 \mathrm{kPa}$ which was used as zero-stress to enable observing of strain during the 20 minutes recovery time. The permanent deformations [\%] were calculated from the ratio of permanent strain after 20 minutes recovery time to maximum strain of the tested film samples.

\section{Results and discussion}

\subsection{Polymerizations}

The preparation of poly(ester-urethane)s consisted of two steps, as shown in Figure 1. The precursors, i.e. soft and hard blocks of a poly(ester-urethane) multiblock copolymer, prepared in the first step differed from each other both structurally and in molecular weights. The three types of soft blocks prepared were amorphous poly(E-caprolactone/D,Llactide) copolymers with number average molar masses around $13000 \mathrm{~g} / \mathrm{mol}$. They differed from each other in molar ratios of monomers CL/DLLA by values of 30/70, 50/50 and 70/30. Each of these three soft blocks were linked separately with two semi-crystalline poly( $\varepsilon$-caprolactone) precursors of different molecular weight, i.e., with hard blocks of different size. The number average molecular weights of the two hard blocks were 22900 and $11500 \mathrm{~g} / \mathrm{mol}$. In addition, soft block P(70/30-1) was linked with a small hard block $\mathrm{P}(100-5)$ with size of $2400 \mathrm{~g} / \mathrm{mol}$. Copolymer precursor $\mathrm{P}(30 / 70-1)$ and PCL precursor $\mathrm{P}(100-0,5)$ were linked as such to act as references and enable comparison with TPEs. The compositions of precursors and TPEs are presented in Table 1 .

The precursors and the PEU elastomers were characterized with SEC and ${ }^{1} \mathrm{H}-\mathrm{NMR}$ both indicating

Formation of polyester precursors

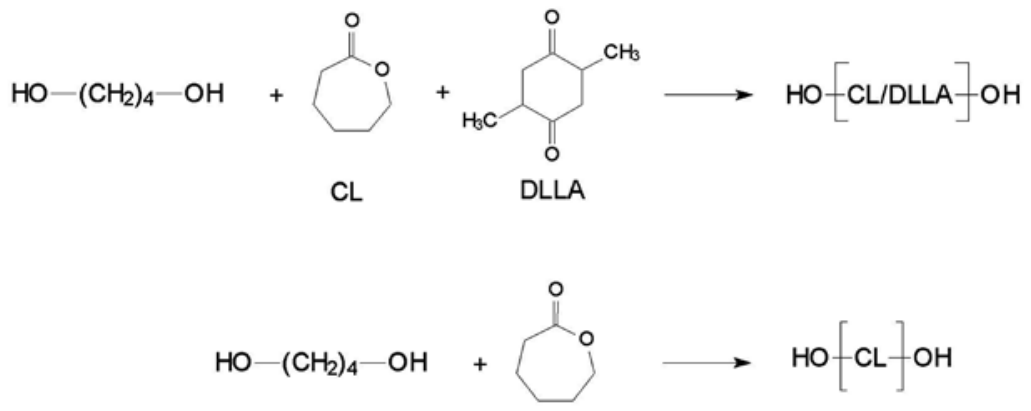

Formation of poly(ester-urethane)
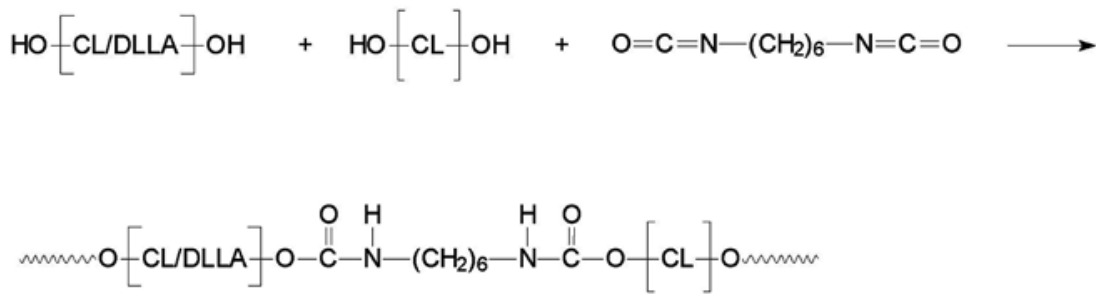

Figure 1. Reaction scheme of poly(ester-urethanes) 
Table 1. Overview of the characterizations of precursors and TPEs

\begin{tabular}{|c|c|c|c|c|c|c|}
\hline Sample & & & & $\mathbf{S E C}^{\mathbf{b}}$ & & ${ }^{1} \mathbf{H}-\mathrm{NMR}$ \\
\hline P(CL/DLLA-BD) & $\begin{array}{c}\mathbf{M}_{\mathbf{n}} \\
{[\mathrm{g} / \mathrm{mol}]}\end{array}$ & $\mathbf{L A}^{\mathbf{a}}$ & $\begin{array}{c}\mathbf{M}_{\mathbf{n}} \\
{[\mathrm{g} / \mathrm{mol}]}\end{array}$ & $\begin{array}{c}\mathbf{M}_{\mathbf{w}} \\
{[\mathrm{g} / \mathrm{mol}]}\end{array}$ & MWD & $\mathbf{L A}^{\mathbf{a}}$ \\
\hline $\mathrm{P}(30 / 70-1)$ & 13600 & 70 & 21700 & 33400 & 1.5 & 71.9 \\
\hline $\mathrm{P}(50 / 50-1)$ & 13000 & 50 & 17200 & 24600 & 1.4 & 48.8 \\
\hline $\mathrm{P}(70 / 30-1)$ & 12400 & 30 & 23400 & 37000 & 1.6 & 31.0 \\
\hline $\mathrm{P}(100-0.5)$ & 22900 & - & 39900 & 59300 & 1.5 & - \\
\hline $\mathrm{P}(100-1)$ & 11500 & - & 25000 & 38500 & 1.5 & - \\
\hline $\mathrm{P}(100-5)$ & 2400 & - & 4900 & 5800 & 1.2 & - \\
\hline ТPE(30/70-1)-b-(100-0.5) & - & 23.3 & 118000 & 304100 & 2.6 & 24.3 \\
\hline ТPE(30/70-1)-b-(100-1) & - & 35.0 & 64700 & 188300 & 2.9 & 35.6 \\
\hline TPE(50/50-1)-b-(100-0.5) & - & 16.7 & 84100 & 276800 & 3.3 & 17.1 \\
\hline TPE(50/50-1)-b-(100-1) & - & 25.0 & 91000 & 212400 & 2.3 & 24.8 \\
\hline TPE(70/30-1)-b-(100-0.5) & - & 10.0 & 86700 & 200100 & 2.3 & 9.6 \\
\hline TPE(70/30-1)-b-(100-1) & - & 15.0 & 113300 & 258800 & 2.3 & 15.5 \\
\hline TPE(70/30-1)-b-(100-5) & - & 25.0 & 97200 & 208300 & 2.1 & 25.8 \\
\hline $\operatorname{refP}(100-0.5)$ & - & - & 156500 & 375200 & 2.4 & - \\
\hline $\operatorname{refP}(30 / 70-1)$ & - & 70 & 63900 & 156100 & 2.4 & 71.1 \\
\hline
\end{tabular}

${ }^{\mathrm{a} D}$,L-lactide units per 100 monomer units

${ }^{\text {b}}$ Determined relative to polystyrene standards

that the polymerizations had been successful. The results are presented in Table 1. Similarly to earlier studies of our group, the molecular weights of the precursors determined by SEC were almost twice the theoretical due to the calibration of the SEC with polystyrene standards [1]. The CL/DLLA ratios in copolymers were calculated from the ${ }^{1} \mathrm{H}$ NMR spectra by comparing the peaks 2,28 ppm for CL and 5,14 ppm for DLLA. The compositions of copolymers were close to theoretical, as seen from the lactide contents shown in the Table 1. After linking reaction the PEUs contained 3-8 precursors as estimated from the number average molecular weights listed in Table 1.

\subsection{Thermal and dynamic mechanical properties}

Thermal and dynamic mechanical properties of precursors and PEUs were characterized by DSC

Table 2. Thermal and dynamic mechanical properties of precursors and TPEs

\begin{tabular}{|c|c|c|c|c|c|c|c|}
\hline Sample & & & & & & & \\
\hline P(CL/DLLA-BD) & $\begin{array}{c}\mathbf{T}_{\mathbf{g}} \\
{\left[{ }^{\circ} \mathbf{C}\right]}\end{array}$ & $\begin{array}{c}\mathbf{T}_{\mathbf{m}} \\
{\left[{ }^{\circ} \mathbf{C}\right]}\end{array}$ & $\begin{array}{c}\Delta \mathbf{H} \\
{[\mathrm{J} / \mathrm{g}]}\end{array}$ & $\begin{array}{c}\text { DCrys } \\
{[\%]}\end{array}$ & $\begin{array}{c}\mathbf{T}_{\mathbf{g}}\left(\mathbf{E}^{\prime \prime}\right) \\
{\left[{ }^{\circ} \mathbf{C}\right]}\end{array}$ & $\begin{array}{c}\mathbf{T}_{\mathrm{g}}(\tan \delta) \\
{\left[{ }^{\circ} \mathrm{C}\right]}\end{array}$ & $\mathbf{H}(\tan \delta)^{\mathbf{a}}$ \\
\hline $\mathrm{P}(30 / 70-1)$ & 8 & - & - & - & & & \\
\hline $\mathrm{P}(50 / 50-1)$ & -13 & - & - & - & & & \\
\hline $\mathrm{P}(70 / 30-1)$ & -41 & - & - & - & & & \\
\hline $\mathrm{P}(100-1)$ & - & 56 & -79 & 57 & & & \\
\hline $\mathrm{P}(100-5)$ & - & 47 & -91 & 65 & & & \\
\hline TPE(30/70-1)-b-(100-0.5) & - & 57 & -39 & 28 & 13 & 16 & 0.31 \\
\hline TPE(30/70-1)-b-(100-1) & - & 55 & -33 & 24 & 11 & 17 & 0.57 \\
\hline TPE(50/50-1)-b-(100-0.5) & -8 & 58 & -41 & 29 & -7 & -3 & 0.25 \\
\hline TPE(50/50-1)-b-(100-1) & -12 & 54 & -25 & 18 & -10 & -3 & 0.45 \\
\hline ТPE(70/30-1)-b-(100-0.5) & -48 & 56 & -48 & 34 & -55 & -33 & 0.09 \\
\hline TPE(70/30-1)-b-(100-1) & -36 & 53 & -39 & 28 & -44 & -23 & 0.18 \\
\hline TPE(70/30-1)-b-(100-5) & -40 & 32 & -4 & 3 & -38 & -26 & 0.47 \\
\hline $\operatorname{refP}(100-0,5)$ & - & 60 & -66 & 47 & - & - & - \\
\hline $\operatorname{refP}(30 / 70-1)$ & 14 & - & - & - & 12 & 21 & 3.29 \\
\hline
\end{tabular}

aHeight of the $\tan \delta$ peak at $T_{g}$ 
and DMA and the results are presented in Table 2. The DSC results were obtained during the second heating scan to erase the thermal history of the sample. In the DSC spectra of copolymer precursors, no signs of melting behavior were detected, supporting the hypothesis of highly transesterified semi-random structure of copolymers leading to amorphous structure. By increasing the DLLA content [mol\%] in the precursor from 30 to 70 , the $T_{g}$ detected increased dramatically from -41 to $+8^{\circ} \mathrm{C}$. For the semi-crystalline PCL precursors $T_{g}$ could not be detected, but the melting peaks in DSC spectra were clear. The degree of crystallinity of PCL precursors varied between 52-65\%. The crystallinity determination was made by comparing of melting enthalpies of precursors with melting enthalpy of $100 \%$ crystalline PCL $(139,5 \mathrm{~J} / \mathrm{g})$ [22]. As assumed, the thermal properties of the precursors were combined in the TPEs. In Figure 2, the DSC spectra of two precursors $\mathrm{P}(50 / 50-1)$ and $\mathrm{P}(100-1)$ as well as the spectrum of the resulting poly(ester-urethane) TPE(50/50-1)-b-(100-1) are plotted one upon the other. In the spectrum of TPE both $T_{g}$ and melting peaks of the precursors are obtained, indicating of successful linking. Both $T_{g}$ and $T_{m}$ of all TPEs were between the corresponding values of precursors. The degree of crystallinity values of TPE-PEUs increased from 3 to $34 \%$, apparently depending on the molecular weight of the hard precursor in the TPE multiblock copolymer. The degree of crystallinity of TPEs was calculated in the same way as for PCL homopolymer precursors by comparing the melting enthalpies of the samples with $100 \%$ crystalline PCL without

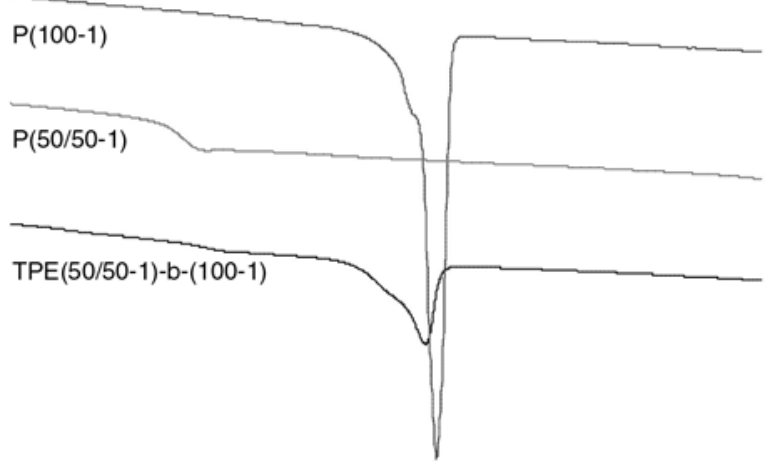

\begin{tabular}{llllllllllll}
\hline-60 & -40 & -20 & 0 & 20 & 40 & 60 & 80 & 100 & 120 & 140 & 160
\end{tabular}

Figure 2. DSC spectra of TPE(50/50-1)-b-(100-1) and the precursors

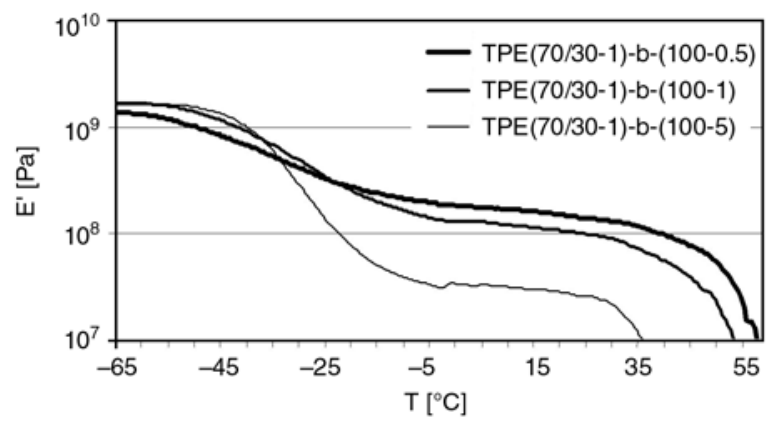

Figure 3. Storage modulus curves of TPEs

normalization to the PCL, the obtained values still being unexpected low $(-10 \ldots-20 \%)$.

DMA was used to study the temperature dependence of the moduli of the PEU elastomers. In a DMA scan, $T_{g}$ was evaluated with two separate values presented in Table 2. These were the temperature where the peak occurred in tan $\delta$ curve and the temperature of the maximum in the loss modulus curve. The height of the $\tan \delta$ peak at $T_{g}$ was presented to express the magnitude of the transition. As expected, both $T_{g}$ values evaluated by DMA were in good correlation with $T_{g}$ values by DSC. As the degree of crystallinity increased, the height of the $\tan \delta$ peak at $T_{g}$ decreased in linear correlation. Similar to cross-linked elastomers [1], the rubbery plateau in the storage modulus curves between $T_{g}$ and terminal flow region was clearly detectable indicating elastic behavior of TPEs. The storage modulus curves of elastomers TPE(70/30-1)-b(100-5), TPE(70/30-1)-b-(100-1) and TPE(70/30-1)b-(100-0.5) are plotted in Figure 3 to emphasize the plateau region. The increasing size of the crystalline PCL block in TPEs lengthened the rubbery plateau towards higher temperatures, as can be seen in the Figure 3.

\subsection{Morphology studies}

The contrast for morphological characterization was examined by TEM. In Figure 4, the TEM images of elastomers A: TPE(70/30-1)-b-(100-5), B: TPE(70/30-1)-b-(100-1) and C: TPE(70/30-1)b-(100-0.5) were plotted next to each other with a view to emphasize the role of the size of the hard block, i.e., degree of crystallinity, in the separation of amorphous and crystalline phases. These and similar series of images can be taken from elastomers consisting of same type of amorphous soft block, differing from each other in the size of the 

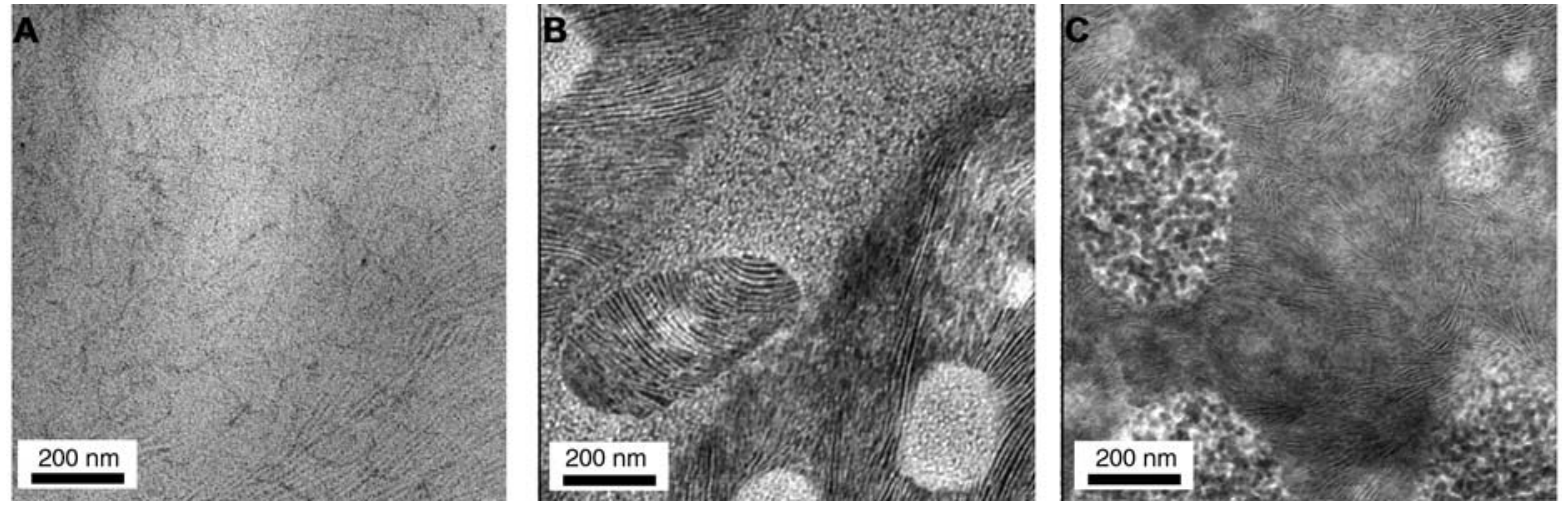

Figure 4. TEM images of elastomers A: TPE(70/30-1)-b-(100-5), B: TPE(70/30-1)-b-(100-1) and C: TPE(70/30-1)-b(100-0.5)

hard block. The degree of crystallinity increases from left to right by the values: A: $3 \%, \mathrm{~B}: 24 \%$ and C: $34 \%$. In the TEM images, dark color indicates the amorphous areas while white is the color of crystalline phase. This results from the tendency of amorphous materials to permeate $\mathrm{RuO}_{4}$ stain more readily than crystalline ones. In all three images, some crystallinity or lamellar areas can be detected, while the images $\mathrm{B}$ and $\mathrm{C}$ show significantly more lamellas than image A. Also, in images B and C the phase separation of amorphous and crystalline areas was clearly detectable.

\subsection{Mechanical properties}

The tensile properties of the PEU-TPEs were measured by Instron 4204 tensile testing machine, and tensile strength, strain and modulus are presented in Figure 5. In the multiblock copolymer TPEs, the tensile properties of both precursors were combined, which is easily observed by comparing the

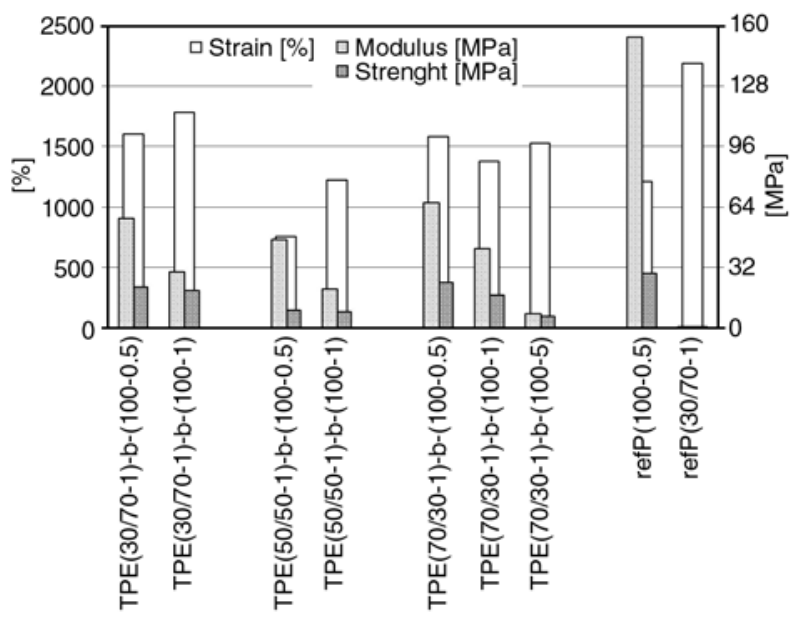

Figure 5. Mechanical properties of elastomers results with results of the reference PEUs denoted refP(100-0.5) and refP(30/70-1). By increasing the molecular weight of the hard block in a PEU-TPE, i.e., increasing the degree of crystallinity, the modulus and strength increased as well. The copolymer with composition of 50/50 had slightly lowest mechanical properties. The elastomers were so resilient that when the gauge lengths of the dogbone specimens were drawn out the specimens only did not break but also the ends of the specimens between the grip holders begun to strain. This caused false strain values by increasing the actual maximum strain percent. However, this quasi-elongation was detectable in strain-stress diagrams, and it was possible to be eliminated from the results. Anyway, the maximum strain percent values of the elastomers were very high, $>2000 \%$. PCL is known to be highly elastic as proved by the reference PEU refP(100-0.5) with maximum strain of $1200 \%$. However, D,L-lactide still increased elongation so that the PEU-TPEs with the highest lactide contents of the soft copolymer block had the highest maximum strain percent values, i.e., from 1600 to $1800 \%$. The fully amorphous reference polymer refP(30/70-1) without crystalline PCL blocks strained $>2000 \%$.

To examine the role of preparation technique of the test specimens to the tensile test results, two TPEs were also tested with extruded specimens. Figure 6 illustrates the difference in results caused most likely by orientation of linear polymer chains during the extrusion. The die-cut samples showed dramatically lower modulus and strength values compared with extruded specimens. This can be explained by the hardening occurred by orientation of polymer chains. Some of the die-cut samples 


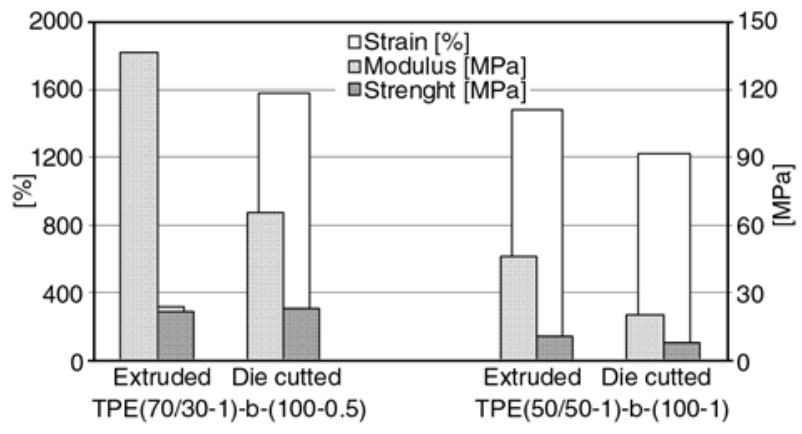

Figure 6. The role of different preparing techniques of the samples in mechanical properties of elastomers

were slightly blistered, and the changes in quality of the specimens might affect results as well.

\subsection{Creep recovery properties}

The creep recovery properties of the TPEs were measured with two different test procedures both using the tensile mode. The first test series were run by Instron 4204 tensile testing machine with dogbone specimens, and second series by DMA Perkin-Elmer 7 Series instrument for film samples. In the first test series the specimens were strained to $100 \%$ elongation once, relaxed, and after $10 \mathrm{~min}$ relaxation time the permanent deformations were measured. The stresses needed for $100 \%$ straining varied much depending on the materials. In the second test series constant stress was applied for 10 min before relaxation to point out the effect of orientation of polymer chains. In both tests, the composition of the amorphous block of the copolymer did not have significant effect on recovery

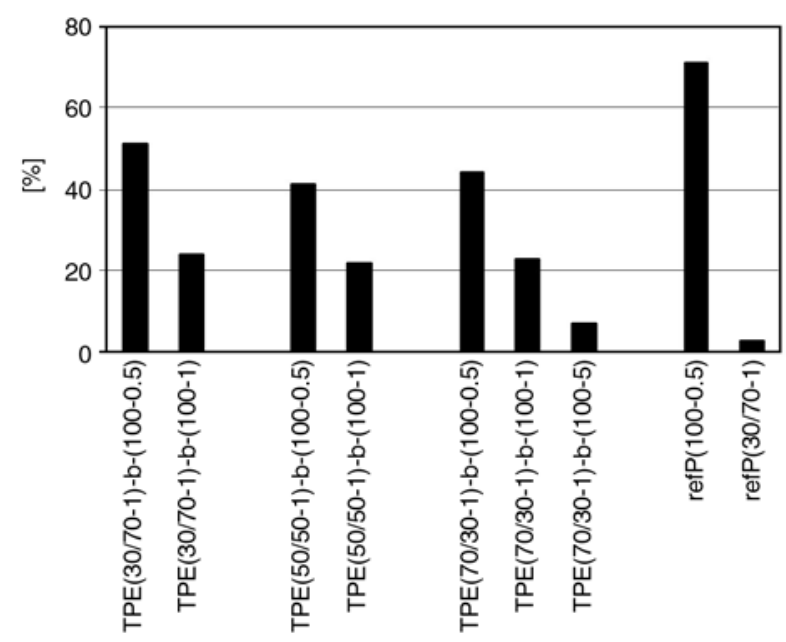

Figure 7. Permanent deformations of elastomers after recovery from $100 \%$ strain properties whereas these properties were mainly dominated by the size of the hard block of them, i.e., the degree of crystallinity. The TPEs having a copolymer with CL/DLLA ratio 50/50 as soft block, recovered slightly worse than other TPEs, as could be expected on basis of tensile testing. The results of the first creep recovery test after 100 percent elongation are presented in Figure 7. The lower the overall degree of crystallinity is the smaller is the permanent deformation of the specimens. These results describe the recovery properties of single, short-term deformation of material when no orientation of polymer chains obviously occurs. When orientation apparently is involved in long-term tests, as in our second test series, the results were different as shown in Figures 8 and 9.

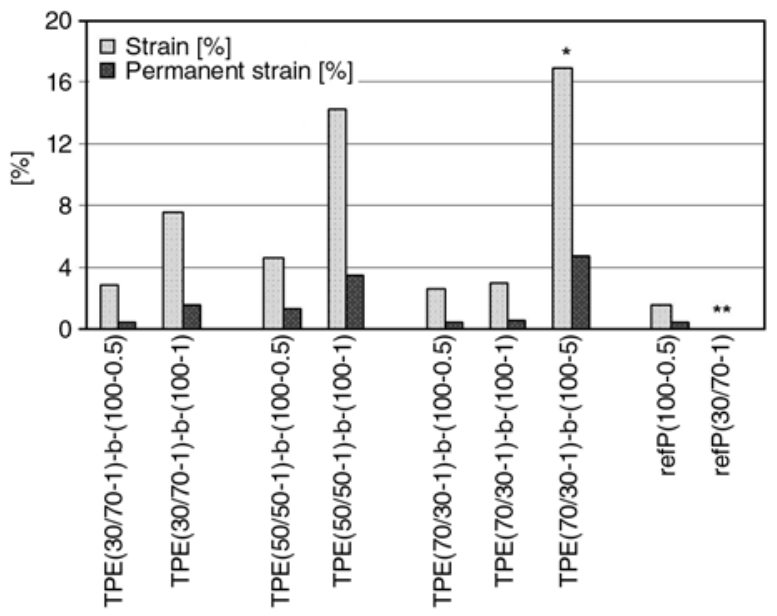

Figure 8. Strain after 10 minutes applied stress $\left(2 \mathrm{~N},{ }^{*} 1 \mathrm{~N}\right)$ and permanent strain after 20 minutes recovery time of elastomers. ( ${ }^{* *}$ Not measured, sample too soft)

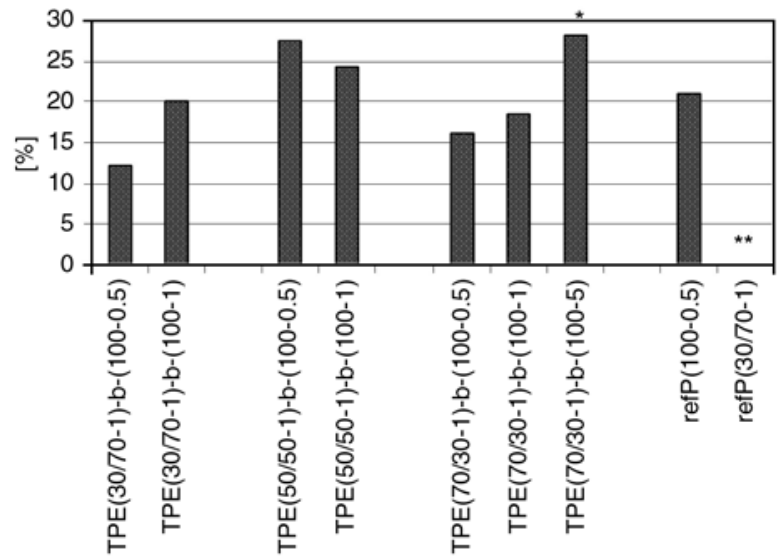

Figure 9. Permanent deformations after 10 minutes applied stress $\left(2 \mathrm{~N},{ }^{*} 1 \mathrm{~N}\right)$ and 20 minutes recovery time of elastomers. (**Not measured, sample too soft) 
Under the same constant stress, TPEs with lower overall degree of crystallinity not only strained more but also the relative permanent deformation was higher than for elastomers with higher degree of crystallinity. This supports the assumption that crystalline phases are required to enhance recovery properties of TPEs.

\section{Conclusions}

In this study, poly(ester-urethane) thermoplastic elastomers (PEU-TPEs) were prepared by simple two-step melt polymerization technique. On basis of tensile testing the products were elastic showing at the same time feasible strength values. The TEM images of the products revealed morphological feature of elastomers by the fact that phase separation of the crystalline and amorphous phases was clearly observed when the degree of crystallinity increased. As known, phase separation is required for good creep resistance. The recovery properties of the products were promising, and by modification of the polymer composition further still better creep resistance can obviously be achieved. The distinct rubbery plateau in storage modulus curves confirmed, too, the elastic behaviour of the TPEs. However, one important feature to be studied in the future is the conservation of mechanical properties during hydrolytic degradation of PEU-TPEs.

\section{Acknowledgements}

This work has been carried out within the Bio- and Nanopolymers Research Group, which is funded by the Academy of Finland (CoE program code number 211493).

\section{References}

[1] Helminen A. O., Korhonen H., Seppälä J. V.: Crosslinked poly( $\varepsilon$-caproplactone/D,L-lactide)copolymers with elastic properties. Macromolecular Chemistry and Physics, 203, 2630-2639 (2002).

[2] Bates F. S., Fredricson G. H.: Block copolymer thermodynamics: Theory and experiment. in: 'Thermoplastic elastomers' (eds.: Holden G., Legge N. R., Quirk R. P., Schroeder H. E.) Hanser/Gardner, Cincinnati, USA, 401-426 (2004).

[3] Hiltunen K., Seppälä J. V., Härkönen M.: Lactic acid based poly(ester-urethanes): Use of hydroxyl terminated prepolymer in urethane synthesis. Journal of Applied Polymer Science, 63, 1091-1100 (1997).
[4] Hiltunen K., Seppälä J. V., Härkönen M.: Lactic acid based poly(ester-urethane)s: The effects of different polymerization conditions on the polymer structure and properties. Journal of Applied Polymer Science, 64, 865-873 (1997).

[5] Härkönen M., Hiltunen K., Malin M., Seppälä J. V.: Properties and polymerization of biodegradable thermoplastic poly(ester-urethane). Journal of Macromolecular Science, Part A: Pure and Applied Chemistry, 32, 857-862 (1995).

[6] Kylmä J., Härkönen M., Seppälä J. V.: The modification of lactic acid based poly(ester-urethane) by copolymerization. Journal of Applied Polymer Science, 63, 1865-1872 (1997).

[7] Kylmä J., Seppälä J. V.: Synthesis and characterization of a biodegradable thermoplastic poly(ester-urethane) elastomer. Macromolecules, 30, 2876-2882 (1997).

[8] Helminen A., Kylmä J., Tuominen J., Seppälä J. V.: Effect of structure modification on rheological properties of biodegradable poly(ester-urethane). Polymer Engineering and Science, 40, 1655-1662 (2000).

[9] Cohn D., Salomon A. H.: Designing biodegradable multiblock PCL/PLA thermoplastic elastomers. Biomaterials, 26, 2297-2305 (2005).

[10] Stirna U. K., Tupureina V. V., Sevast'yanova I. V., Dzene A. V., Misane M. M., Vilsone D. M.: Synthesis, structure, and properties of poly(ester-urethanes) based on glycerol monostearate. Polymer Science, Series A, 45, 765-772 (2003).

[11] Teng C., Yang K., Ji P., Yu M.: Synthesis and characterization of poly(L-lactic acid)-poly( $\varepsilon$-caprolactone) multiblock copolymers by melt polycondensation. Journal of Polymer Science, Part A: Polymer Chemistry, 42, 5045-5053 (2004).

[12] Huang M-H., Li S., Vert M.: Synthesis and degradation of PLA-PCL-PLA triblock copolymer prepared by successive polymerization of $\varepsilon$-caprolactone and DL-lactide. Polymer, 45, 8675-8681 (2004).

[13] Zhang Z., Grijpma D. W., Feijen J.: Triblock copolymers based on 1,3-trimethylene carbonate and lactide as biodegradable thermoplastic elastomers. Macromolecular Chemistry and Physics, 205, 867-875 (2004).

[14] Kim J-H., Lee S. Y., Chung D. J.: Synthesis and properties of triblock copolymers from L-lactide and trimethylene carbonate. Polymer Journal, 32, 10561059 (2000).

[15] Pospiech D., Komber H., Jehnichen D., Häussler L., Eckstein K., Scheibner H., Janke A., Kricheldorf H. R., Petermann O.: Multiblock copolymers of L-lactide and trimethylene carbonate. Biomacromolecules, 6 , 439-446 (2005).

[16] Frick E. M., Hillmyer M. A.: Synthesis and characterization of polylactide-block-polyisoprene-block-polylactide triblock copolymers: New thermoplastic elastomers containing biodegradable segments. Macromolecular Rapid Communications, 21, 1317-1322 (2000). 
[17] Messman J. M., Scheuer A. D., Storey R. F.: Synthesis and characterization of A-B-A triblock copolymers derived from chloro-telechelic poly(L-lactide): Combining ring-opening polymerization $(\mathrm{ROP})$ and atom transfer radical polymerization (ATRP). Polymer, 46, 3628-3638 (2005)

[18] Jeon O., Lee S-H., Kim S. H., Lee Y. M., Kim Y. H.: Synthesis and characterization of poly(L-lactide)poly( $\varepsilon$-caprolactone) multiblock copolymers. Macromolecules, 36, 5585-5592 (2003).

[19] Cohn D., Hotovely-Salomon A.: Biodegradable multiblock PEO/PLA thermoplastic elastomers: Molecular design and properties. Polymer, 46, 2068-2075 (2005).
[20] Hiljanen-Vainio M., Karjalainen T., Seppälä J. V.: Biodegradable lactone copolymers. I. Characterization and mechanical behavior of $\varepsilon$-caprolactone and lactide copolymers. Journal of Applied Polymer Science, 59, 1281-1288 (1996).

[21] Brown G. M., Butler J. H.: New method for the characterization of domain morphology of polymer blends using ruthenium tetroxide staining and low voltage scanning electron microscopy (LVSEM). Polymer, 38, 3936-3945 (1997).

[22] Perrin D. E., English J. P.: Polycaprolactone. in 'Handbook of Biodegradable Polymers' (eds.: Domb A. J., Kost J., Wiseman D. M.) Harwood Academic Publishers, Amsterdam, 63-77 (1997). 